\title{
Erratum
}

\section{Copper in Alzheimer's Disease: A Meta-Analysis of Serum, Plasma, and Cerebrospinal Fluid Studies}

\author{
Mariacarla Ventriglia $^{\mathrm{a}, \mathrm{b}}$, Serena Bucossi ${ }^{\mathrm{a}}$, Valentina Panetta ${ }^{\mathrm{c}, \mathrm{d}}$ and Rosanna Squitti ${ }^{\mathrm{a}, \mathrm{b}, *}$ \\ a Department of Neurology, "Campus Biomedico" University, Rome, Italy \\ ${ }^{\mathrm{b}}$ Department of Neuroscience, AFaR - Fatebenefratelli Hospital, Isola Tiberina, Rome, Italy \\ ${ }^{\mathrm{c}}$ Medical Statistics and Information Technology, AFaR - Fatebenefratelli Hospital, Isola Tiberina, \\ Rome, Italy \\ ${ }^{\mathrm{d}}$ L'altrastatistica srl-Consultancy and Training-Biostatistics office, Rome, Italy
}

\begin{abstract}
This contribution reviews and corrects data from our previous meta-analysis, which appeared in the Journal of Alzheimer's Disease in 2011 concerning the role of copper in Alzheimer's disease. We repeated the meta-analysis after excluding four of the five studies from our laboratory to avoid possible bias in the result. In addition, we included two studies on serum copper levels in Alzheimer's disease not previously considered. The results indicate higher levels of copper in Alzheimer's disease patients than in controls, confirming our previous conclusion.
\end{abstract}

Keywords: Alzheimer's disease, copper, meta-analysis, serum

We read with great interest the study appeared in the Journal of Alzheimer's Disease by Mueller and colleagues [1] on abnormalities of copper and iron homeostasis predicting cognitive decline in mild cognitive impairment. When discussing their results, the authors commented on the meta-analysis by Bucossi and co-workers [2]. The authors raised two concerns about the results of the meta-analysis that deserve attention and could certainly improve the quality of the meta-analysis already published. Specifically, they questioned the outcome of the meta-analysis, ascribing the result on serum studies to a bias originating from the fact that a bulk of the studies were carried out in

\footnotetext{
${ }^{*}$ Correspondence to: Dr. Rosanna Squitti, PhD, Department of Neuroscience, AFaR - Osp. Fatebenefratelli, 00186, Rome, Italy. Tel.: +39 $06 \quad 6837 \quad 385 /+3906 \quad 6837 \quad 300$; E-mail: rosanna.squitti@afar.it.
}

the same (i.e., our) laboratory. However, in the published meta-analysis, in order to check for a possible bias that could have affected the results, we repeated the meta-analysis after excluding four of the five studies from our laboratory [3-6]. After this exclusion, the meta-analysis confirmed a higher copper level in AD patients compared to healthy controls (reported in Results, studies on copper and plasma, last paragraph) [2].

As to their second concern, Mueller and colleagues correctly note that two studies $[7,8]$ were not included in the meta-analysis. We thank the authors for bringing these two studies to our attention, even though the study of Molaschi and co-workers [7] actually does not support our inclusion on the basis of the inclusionexclusion criteria used in the published meta-analysis.

We performed the current meta-analyses following the inclusion-exclusion criteria precisely and 


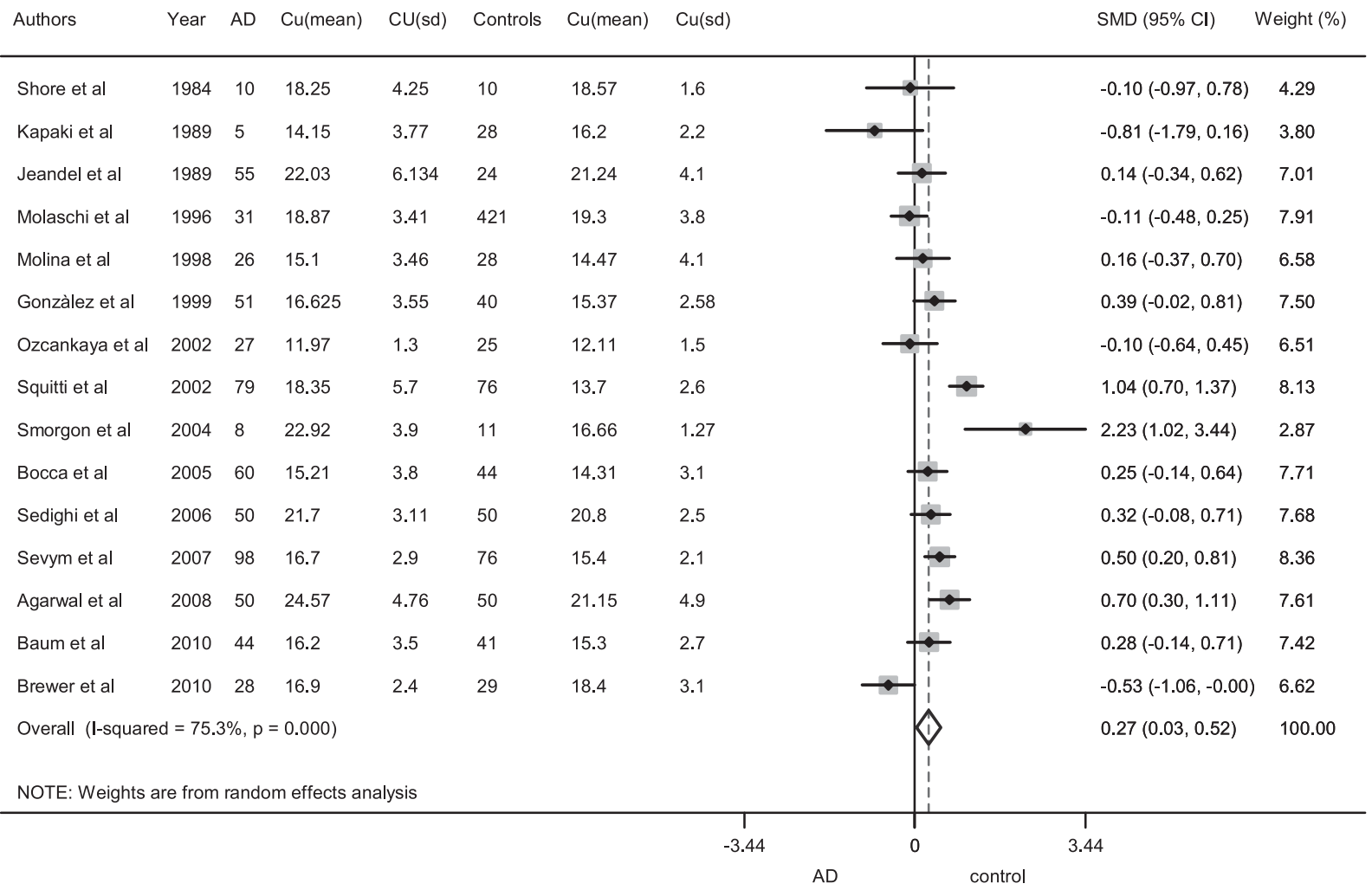

Fig. 1. Standardized mean difference (SMD) computed from the studies on Cu serum levels ( $\mu$ mol/L) [7-9, 11-22]. SMDs between patients and controls are represented by squares, whose sizes are proportional to the sample size of the relative study. The whiskers represent the $95 \%$ confidence interval (CI). The diamond represents the pooled estimate based on the random effects model, with the centre representing the point estimate and the width the associated 95\% CI. Heterogeneity Chi-squared $=56.71$ (d.f. $=14), p<0.000$. I-squared (variation in SMD attributable to heterogeneity) $=75.3 \%$. Estimate of between-study variance Tau-squared $=0.1618$; Test of SMD $=0: z=2.19, p=0.029$.

following procedures detailed in our previous metaanalysis [2].

To reply to both concerns, we have run two additional meta-analyses, both including the studies by Molaschi and co-coworkers [7] and by Shore and colleagues [8]. Figure 1 shows the results when just one study from our laboratory [9] is included in the metaanalysis. The results indicate that serum copper levels were significantly higher in AD patients than in healthy controls. Figure 2 shows the results when the two studies mentioned above are included in the meta-analysis together with the same studies taken into account in the already published meta-analysis [2]. Again, the results indicate higher levels of copper in $\mathrm{AD}$ patients than in controls.

It is imperative to carefully consider meta-analyses or reviews that claim to objectively evaluate data collected over a long period of time as Mueller and co-workers [1] suggested in this discussed case and
Schrag and colleagues [10] have previously pointed out. We have taken this opportunity to revise and correct our previous incomplete data but also to strengthen our conclusion.

\section{ACKNOWLEDGMENTS}

This work was supported by the following grants: 1) European Community's Seventh Framework Programme Project MEGMRI (n. 200859). 2) FISM - Fondazione Italiana Sclerosi Multipla Cod.2010/R/38"Fatigue Relief in Multiple Sclerosis by Neuromodulation: a transcranial Direct Current Stimulation (tDCS) Intervention. [FaMuSNe]; 3) Italian Ministry of Health Cod. GR-2008-1138642 'Promoting recovery from Stroke: Individually enriched therapeutic intervention in Acute phase' [ProSIA] 3) Italian Health Department: "Profilo 


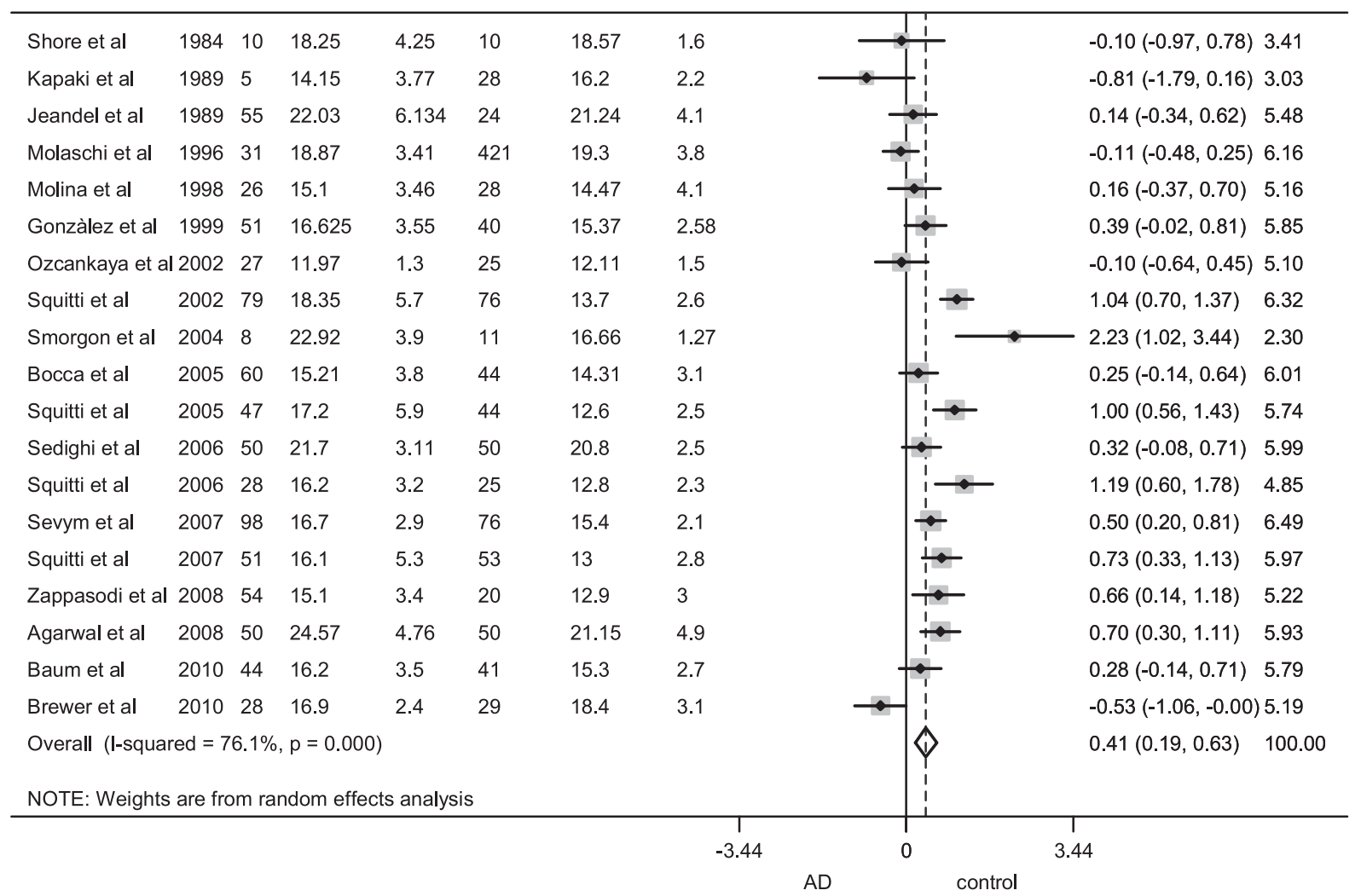

Fig. 2. Standardized mean difference (SMD) computed from the studies on $\mathrm{Cu}$ serum levels ( $\mu$ mol/L) [3-9, 11-22]. SMDs between patients and controls are represented by squares, whose sizes are proportional to the sample size of the relative study. The whiskers represent the $95 \%$ confidence interval (CI). The diamond represents the pooled estimate based on the random effects model, with the centre representing the point estimate and the width the associated 95\% CI. Heterogeneity Chi-squared $=75.22$ (d.f. $=18), p<0.000$. I-squared (variation in SMD attributable to heterogeneity) $=76.1 \%$. Estimate of between-study variance Tau-squared $=0.1710$; Test of SMD $=0: z=3.61, p=0.000$.

Biologico e Genetico della Disfunzione dei Metalli nella Malattia di Alzheimer e nel 'Mild Cognitive Impairment' " [RF 2006 conv. 58].

\section{REFERENCES}

[1] Mueller C, Schrag M, Crofton A, Stolte J, Muckenthaler MU, Magaki S, Kirsch W (2012) Altered serum iron and copper homeostasis predicts cognitive decline in mild cognitive impairment. J Alzheimers Dis 29, 341-350.

[2] Bucossi S, Ventriglia M, Panetta V, Salustri C, Pasqualetti P, Mariani S, Siotto M, Rossini PM, Squitti R (2011) Copper in Alzheimer's disease: A meta-analysis of serum, plasma, and cerebrospinal fluid studies. J Alzheimers Dis 24, 175-185.

[3] Squitti R, Barbati G, Rossi L, Ventriglia M, Dal Forno G, Cesaretti S, Moffa F, Caridi I, Cassetta E, Pasqualetti P, Calabrese L, Lupoi D, Rossini PM (2006) Excess of nonceruloplasmin serum copper in AD correlates with MMSE, CSF [beta]-amyloid, and h-tau. Neurology 67, 76-82.
[4] Squitti R, Pasqualetti P, Dal Forno G, Moffa F, Cassetta E, Lupoi D, Vernieri F, Rossi L, Baldassini M, Rossini PM (2005) Excess of serum copper not related to ceruloplasmin in Alzheimer disease. Neurology 64, 1040-1046.

[5] Squitti R, Ventriglia M, Barbati G, Cassetta E, Ferreri F, Dal Forno G, Ramires S, Zappasodi F, Rossini PM (2007) 'Free' copper in serum of Alzheimer's disease patients correlates with markers of liver function. J Neural Transm 114, 15891594.

[6] Zappasodi F, Salustri C, Babiloni C, Cassetta E, Del Percio C, Ercolani M, Rossini PM, Squitti R (2008) An observational study on the influence of the APOE-epsilon4 allele on the correlation between 'free' copper toxicosis and EEG activity in Alzheimer disease. Brain Res 1215, 183-189.

[7] Molaschi M, Ponzetto M, Bertacna B, Berrino E, Ferrario E (1996) Determination of selected trace elements in patients affected by dementia. Arch Gerontol Geriatr 22(Suppl 1), 3942.

[8] Shore D, Henkin RI, Nelson NR, Agarwal RP, Wyatt RJ (1984) Hair and serum copper, zinc, calcium, and magnesium concentrations in Alzheimer-type dementia. J Am Geriatr Soc 32, 892-895 
[9] Squitti R, Lupoi D, Pasqualetti P, Dal Forno G, Vernieri F, Chiovenda P, Rossi L, Cortesi M, Cassetta E, Rossini PM (2002) Elevation of serum copper levels in Alzheimer's disease. Neurology 59, 1153-1161.

[10] Schrag M, Mueller C, Oyoyo U, Smith MA, Kirsch WM (2011) Iron, zinc and copper in the Alzheimer's disease brain: A quantitative meta-analysis. Some insight on the influence of citation bias on scientific opinion. Prog Neurobiol 94, 296306.

[11] Agarwal R, Kushwaha SS, Tripathi CB, Singh N, Chillar N (2008) Serum copper in Alzheimer's disease and vascular dementia. Indian J Clin Biochem 23, 369-374.

[12] Baum L, Chan IH, Cheung SK, Goggins WB, Mok V, Lam L, Leung V, Hui E, Ng C, Woo J, Chiu HF, Zee BC, Cheng W, Chan MH, Szeto S, Lui V, Tsoh J, Bush AI, Lam CW, Kwok T (2010) Serum zinc is decreased in Alzheimer's disease and serum arsenic correlates positively with cognitive ability. Biometals 23, 173-179.

[13] Bocca B, Forte G, Petrucci F, Pino A, Marchione F, Bomboi G, Senofonte O, Giubilei F, Alimonti A (2005) Monitoring of chemical elements and oxidative damage in patients affected by Alzheimer's disease. Ann Ist Super Sanita 41, 197-203.

[14] Brewer GJ, Kanzer SH, Zimmerman EA, Celmins DF, Heckman SM, Dick R (2010) Copper and ceruloplasmin abnormalities in Alzheimer's disease. Am J Alzheimers Dis Other Demen 25, 490-497.

[15] Gonzalez C, Martin T, Cacho J, Brenas MT, Arroyo T, GarciaBerrocal B, Navajo JA, Gonzalez-Buitrago JM (1999) Serum zinc, copper, insulin and lipids in Alzheimer's disease epsilon 4 apolipoprotein E allele carriers. Eur J Clin Invest 29, 637642 .
[16] Jeandel C, Nicolas MB, Dubois F, Nabet-Belleville F, Penin F, Cuny G (1989) Lipid peroxidation and free radical scavengers in Alzheimer's disease. Gerontology 35, 275282.

[17] Kapaki E, Segditsa J, Zournas C, Xenos D, Papageorgiou C (1989) Determination of cerebrospinal fluid and serum lead levels in patients with amyotrophic lateral sclerosis and other neurological diseases. Experientia 45, 1108-1110.

[18] Molina JA, Jimenez-Jimenez FJ, Aguilar MV, Meseguer I, Mateos-Vega CJ, Gonzalez-Munoz MJ, de Bustos F, Porta J, Orti-Pareja M, Zurdo M, Barrios E, Martinez-Para MC (1998) Cerebrospinal fluid levels of transition metals in patients with Alzheimer's disease. J Neural Transm 105, 479488.

[19] Ozcankaya R, Delibas N (2002) Malondialdehyde, superoxide dismutase, melatonin, iron, copper, and zinc blood concentrations in patients with Alzheimer disease: Crosssectional study. Croat Med J 43, 28-32.

[20] Sedighi B, Shafa MA, Shariati M (2006) A study of serum copper and ceruloplasmin in Alzheimer's disease in Kerman, Iran. Neurology Asia 11, 107-109.

[21] Sevym S, Unal O, Tamer L, Doğu O, Ozge A (2007) Can serum levels of copper and zinc distinguish Alzheimer's patients from normal subjects? J Neurol Sci (Turkish) 24, 197-205.

[22] Smorgon C, Mari E, Atti AR, Dalla Nora E, Zamboni PF, Calzoni F, Passaro A, Fellin R (2004) Trace elements and cognitive impairment: An elderly cohort study. Arch Gerontol Geriatr Suppl 9, 393-402. 